\title{
Place and Space in the Design of New Learning Environments
}

\author{
Dr Peter Jamieson, Monash University \\ Kenn Fisher, Flinders University \\ Dr Tony Gilding, Victoria University of Technology \\ Dr Peter G. Taylor, Griffith University \\ Dr A.C.F. (Chris) Trevitt, Australian National University
}

\begin{abstract}
The development of online and virtual teaching and learning environments to augment formal face-to-face environments raises questions about the way the new communication and information (CIT) technologies are being incorporated into the on-campus environment. More importantly, this development challenges the meaning of the on-campus student learning experience. The new CITs require institutions, teachers and researchers to reconsider the relationship of the physical setting to the student learning experience. The paper highlights examples of recent developments of new learning environments which have been enhanced by the contribution of educational developers at several Australian universities. It also proposes a set of pedagogically-informed principles to guide the development of on-campus teaching and learning environments (which may feature the use of CITs).
\end{abstract}

\section{Introduction}

A number of Australian universities have recently commissioned major building projects to provide improved campus facilities and to project a more attractive and modern image in an increasingly competitive higher education market (Howlin, 1999). Despite a plethora of architectural awards and positive reviews for new university buildings (Day, 1999; Rollo, 1996), the performance of these facilities as contemporary places for teaching and learning is open to question. In order to meet its primary purpose, university architecture must do more than appeal aesthetically to users, passers-by or judges of architectural awards. The idea that the formal teaching and learning process 'takes place' somewhere needs to be acknowledged by university administrators, facility managers and architects, educational researchers and teachers and be a primary consideration in the design of new buildings or the redevelopment of existing facilities.

There is much more to space and place than meets the eye. Winston Churchill is reported to have observed that "We shape our buildings and afterwards our buildings shape us".

Elaborating this theme, a practicing architect, observes that architecture:

...is a social practice and as such cannot avoid being part of a complex network of power relationships. The fact that it impacts upon the production of ....the built environment clearly indicates the political implications of aesthetic control. Space is neither innocent nor neutral: it is an instrument of the political; it has a performative aspect whoever inhabits it; it works on its occupants. At the micro level, space prohibits, decides what may occur, lays down the law, implies a certain order, commands and locates bodies. (Pouler, cited in Scheer \& Preiser 1994, p. 175)

Traditionally, on-campus university teaching has taken place in lecture theatres, tutorial rooms and laboratories. In this context, the physical environment is integral to the process, and largely taken-as-given (Taylor, 1996). Thus, the size and form of a lecture theatre governs much of the teaching that happens within it. It is an environment focused on the teacher's presentation. Although the physical context's influence will vary from teacher to teacher, the physical environment is bound to play a significant role in how teachers approach their teaching or how they view what is possible within a particular place. 
The link between place and behaviour is immediately obvious when the theory and practice of distance education is considered. Distance education has been primarily concerned with the mechanism for developing and delivering programs to off-campus students. First, through the use of print-based materials and more recently by applying various communication and information technologies (CITs), distance education has been about overcoming the physical distance which separates the student's place and the teacher/institution's place. In these circumstances, the physical separation of participants has generally been regarded as evidence of an inferior pedagogy compared to the regular on-campus situation, with distance education being defined in terms of what it isn't (not face-to-face) rather than what it is (Bagnall, 1988; Gillard, 1993).

The increasing on-campus use of CITs is changing the way universities conduct one of their core activities: teaching. Although the strategic emphasis placed on CITs differs markedly across Australian institutions (Moffatt \& Flynn, 1998; Ryan \& Tapsall, 1998), new learning environments which incorporate or are predicated on the use of CITs will be an increasingly important element of students' learning experiences. This fundamental change to the fabric of university teaching represents a conundrum for institutions which have traditionally conducted all or most of their teaching in on-campus, face-to-face mode. The enhancement of face-to-face teaching with the use of CITs represents a shift from campus-bound activities enabling increased flexibility over when, where, what, how and with whom students learn. In this changing context, this paper will specifically address the importance of physical place to those pedagogical processes which remain on-campus. In this context, what type of built environments are universities offering students? What power relations are embedded in the physical design of on-campus institutions and are these consistent with more student-centred approaches to learning?

In this paper, the pedagogy-place nexus will be examined from an educational and architectural perspective in order to highlight the necessarily multi-disciplinary approach which needs to be brought to bear on this issue. The paper is based on the experiences of the authors in our various roles. One of us, Kenn Fisher, has considerable national and international experience in the design of educational facilities. The others have staff and organisational development roles directly related to the introduction and development of new

learning environments in our respective universities. In those roles each has had made specific and ongoing contributions to the pedagogy-space design of particular learning places. This paper represents an attempt to distil our collective thinking about these issues.

\section{The present response to CITs}

Contrary to some predictions, the rise in use of CITs is unlikely to see traditional on-campus universities replaced by mega online, corporate institutions (Ryan \& Tapsall, 1998). Instead, they invite a reconsideration of the structure and function of existing universities and may become the catalyst for fundamentally rethinking how the on-campus teaching and learning process is conducted. Critical questions concerning the pedagogical process, architectural assumptions and the role of educational technologies need to be addressed. What is the nature and purpose of face-to-face interaction in the teaching and learning process? How can the CITs be effectively integrated into the on-campus environment to enhance existing approaches to teaching and learning? What type of on-campus environments (formal and informal) should universities provide which are not predicated on CITs playing the essential role in pedagogy? What type of teaching and learning facilities need to be provided for oncampus learners and teachers? While all of these questions demand attention, it is the latter which is the immediate focus. 
The new CITs undoubtedly have much to contribute, but if university staff and students are to reap the benefits while simultaneously minimising the losses, a more informed approach to integrating them into the on-campus environment must be found. Too often, existing facilities which do not meet user needs in terms of comfort or basic-use have become repositories for these new technologies. In many instances technologies (usually personal computers) are installed in classrooms or other spaces in a manner which maximises the presence of the technology, and resulting in the creation of the 'battery hen' computer laboratory. Typically, such laboratories are fitted with cheap, often inappropriate furniture and fittings which defy ergonomic principles, fail to accommodate the use of non-IT resources, and offer little scope for student-student interaction without impeding other users. Ironically, this type of environment serves to isolate the student as an individual learner, binding them to a single computer in a situation often characterised by overcrowding. The potential for student-student interaction is rarely realised due to the layout and fit of the facility, as well as the way it has been represented to the student in terms of the type of behaviour which should be enacted in that place (ie individual computer use). In general this practice has produced teaching and learning environments which are both inadequate and outdated on architectural and pedagogical grounds.

At the beginning of the 1990s, a Federal Government report acknowledged the impending impact of the new technologies on university teaching. In reviewing technological advances it stated:

Education in all institutions is becoming multi-media education ... through the enterprise of academics and the demands of students, the thoroughly conventional classroom lecture plus tutorial, with no other mode of delivery or interaction, may in our lifetime become a minority activity in universities. (National Board of Employment, Education and Training 1993, p. 27)

The challenge facing predominantly on-campus institutions is to balance the development of an online teaching presence and the redesign of their existing built environments where teaching will continue to be transacted. This is both a matter of resource management and strategic educational planning.

\section{Constructing knowledge in 'place'}

The architectural model of a university, comprising the teaching spaces (lecture theatres, tutorial rooms, laboratories, libraries), administrative areas and social and leisure environments, remained largely unchanged throughout the twentieth century. One of the fundamental characteristics of this model, which usually attracts little critical attention, is the basic separation of teacher offices and work areas from student learning areas or classrooms. This arrangement typifies an authority structure and power relation that undermines the creation of the more collaborative learning communities which universities claim in their vision statements and in their student-centred teaching and learning policies (eg, see http://www.monash.edu.au/info/teaching.htm or http://www.gu.edu.au/ua/aa/tal/home.html. This traditional architectural-pedagogical paradigm informs many recent on-campus developments. The result is that while new campus developments present architecturally challenging building types, they continue to reinforce teacher-centred pedagogical practices.

At the same time, thinking about the relationship of the student to the on-campus environment has gradually shifted to a point where alternative perspectives of the student-campus relationship have been articulated. For instance, Cecelia Merkel (1999) brings a folkloric perspective to the study of the disparate communities formed through their relationships to specific on-campus locations. Donald Norris (1999) introduces the concept of fused-use 
environments, where fusion involves both diverse activities and the material with the virtual. Peter Radloff (1998) advances the idea of a 'learning ecology' to encompass the multiple dimensions of a student's on-campus existence which directly affect their learning experience. His concept takes us beyond the walls of the common teaching facilities into the greater campus environment. Radloff, drawing on earlier studies, stresses the crucial role which open space plays in campus life. He contends that universities can only support communities of scholars through an institutional commitment to construct an integrated physical, cultural and organisational environment to achieve strategic pedagogical outcomes. At a social level he advocates increased opportunities for shared interaction amongst the entire student population which would require appropriate buildings and open space as well as an appropriate institutional culture. Another improvement he proposes is the use of shortened lecture periods to provide individual students with more opportunities for reflective thought.

The issue of the on-campus built environment has not been a primary concern in the literature dealing with the teaching and learning process in higher education. The absence of concern with the place of teaching and learning is evident in the influential student learning literature that has emerged since the 1970s (Marton \& Saljo, 1976; Entwistle \& Ramsden, 1983; Biggs, 1999). Overall, that body of research unproblematically offered a concept of the teaching and learning transaction as a relation between teacher-student-content unrelated to the physical location of the individual teacher or student (Jamieson, 1998). As this discourse unfolded the idea that teaching and learning was context dependent was put forward, however the concept of 'context' was narrowly defined, for example, in terms of classroom climate (Biggs, 1993), or departmental procedures including assessment (Ramsden, 1992). This also tends to ignore the extensive (and concurrently developed) literature that insists on the fundamental importance of the 'cultural' understandings that students' bring to their learning experiences, from Freire's (1973) concern with 'critical consciousness' to social constructivist views of learning (McWilliam \& Taylor, 1998).

Most recently the research on student learning has focused on the 'experience' of learning (Biggs, 1999; Marton \& Booth, 1997) and the concepts of a student's approach to learning and a teacher's approach to teaching (Prosser \& Trigwell, 1999). However, and despite this shift away from very specific learning or teaching situations to broader research topics, the relationship between physical place and how a student experiences learning or a teacher approaches teaching is not a primary concern. A cynical view might be that it is the conservative nature of the pedagogical researchers and practitioners themselves which has actually eliminated consideration of the physical environment from any serious and deep analysis of teaching and learning. It is the one variable that is taken as fixed. Spatial cognition is largely an unconscious process as it has been 'domesticated' through formative experiences of living in our own homes (Bachelard, 1964).

\section{Constructing knowledge in 'place' and 'space'}

Whilst on-campus teaching and learning environments are founded in a physical place, the introduction of new CITs has complicated the nature of the learning environment and a student's (or a teacher's) relationship/s to, and within, it. These environments include both physical place $(s)$ and electronic space $(s)$. For example, cross-campus video conferencing creates electronic classroom environments made up of multiple places and groups linked in real-time interaction (Jamieson, 1998). In this situation, students may be located in a physical place with other students and a teacher whilst simultaneously interacting with/in an electronic classroom space with physically separated participants with whom they may have no other contact. For students at a site remote from the teaching site, there may be no opportunity for direct physical contact with the teacher or the other students. In this situation, participants in a 
cross-campus video conferencing environment will interact differently to those in a regular classroom as the process is mediated through the audio and video links provided by the system. Unlike a regular classroom, what a participant sees and hears is totally dependent on the technology with the critically important embodied communications unavailable to their knowledge construction (McWilliam \& Taylor, 1998).

The complexity of the new online teaching and learning environments is also apparent when students and teachers choose, or are required, to work in synchronous or asynchronous virtual teaching and learning spaces. Access to those technological environments may be made from a multitude of physical places (eg. on-campus computer laboratory, on-campus office, home, student workplace, etc).

Although it is the online dimension of these new learning environments which is the current focus of university administrators and educational researchers, the location from which the individual participant accesses the online environment is an integral element in the participant's learning experience. For example, the importance of the physical location of online participants, and the effect it has on forming a sense of the individual's identity for other participants, is acknowledged by Worthington (1999). She describes her requirement for online participants to commence their collaboration by offering a description of the physical location from which they enter the virtual classroom site. In her role as teacher she also provides on the internet site

a new picture each week to show the students the space (my surroundings)

of their virtual classroom. Seasonal changes of Victoria B.C. done with my digital camera, etc.

A teacher or student may be actively engaged in an online activity or discussion whilst simultaneously being involved in a separate activity at their physical location. Alternatively, a participant working online may be interrupted by someone approaching them in their physical location about matters unrelated to their immediate learning activity. Similarly, a participant's physical location and their relationship to it (eg a domestic site where household duties impose) may dictate the amount of access they have to an online site, thereby restricting their capacity to contribute to shared activities or to access essential course materials. Clearly there is a need to acknowledge that there is more than just CITs and multimedia in these new learning environments. How might we do this?

\section{Current designs for new on-campus learning environments}

A cursory review of current practice across Australian institutions shows there are two basic approaches to thinking about and implementing on-campus facilities which integrate new technologies. In either case, teachers and students rarely, in the authors' experience, have meaningful input into the design of facilities. One approach involves the redesign of an existing location. This is often led by an institution's facilities management staff whose primary goal is to install new equipment while maintaining a room's established use. The proliferation of 'battery hen' computer laboratories has already been cited as an outcome of this approach. Similarly, in many lecture theatres simple but effective technologies such as whiteboards have been replaced by expensive projection facilities which are basically intended to provide powerful presentational aides for teacher-centred approaches to teaching.

In the second instance, new facilities are designed by architects who necessarily make critical assumptions about how teachers and students will act, founded on established ideas about the architecture of lecture theatres, tutorial rooms or computer laboratories and the spatial and pedagogical relation of these facilities to one another. This approach tends to result in the reproduction of the existing architectural-pedagogical paradigm. For example, new computer 
laboratories often incorporate advanced hardware and software whilst being founded on the established pattern of use involving one student per computer. In these circumstances the opportunity for students to work collaboratively, or in ways that do not directly involve the technology, can be inhibited by the built environment. Operating within the same paradigm, purpose built cross-campus video conferencing classrooms have duplicated the traditional model of the fixed seat, theatre-style and teacher-centred space.

Less than optimal spatial outcomes of the type described above are largely the result of two factors. First, teaching is a contested practice and it is difficult for a university to convey a unified view of the approach to teaching that may be undertaken in any specific area of a building. This is exacerbated when facilities are being designed to support emergent (as distinct from traditional) pedagogical practices. The authors' experience suggests that the assumptions about intended pedagogies that underpin project design briefs tend to be unstated, or unknown to, or unshared by those who are to use the facilities.

Secondly, the building procurement process and the complex supply chain in place in universities is led largely by facility management professionals. Designers tend to be separated from the ultimate building inhabitants by a builder, a project manager and a facility manager, a separation that makes the re-negotiation of architecture-pedagogy assumptions quite difficult. Architects are also saddled with additional boundary conditions such as restricted budgets, increasingly complex building codes and regulatory requirements, and tight time frames. Add to this their propensity to create in isolation (a product of the often adversarial architectural school pedagogy, of the profession itself and the awards mentality driven desire for iconoclastic designs), and a participatory or social form of design process is all but a dream in most cases. What new assumptions might inform this work?

\section{Toward a set of guiding principles for the development of on-campus teaching and learning facilities}

To help counter this historical position, we offer the following set of principles to help inform the design and implementation of built environments for universities. These principles, based on emergent ideas of student-centred, flexible learning, are intended to result in facilities which are less prescribed and function-specific than is presently the case. Their application is intended to foster a sense of ownership by individual communities created through the use and occupation of specific locations on-campus. We see their use as augmenting rather than replacing in toto existing design principles. They express a new emphasis in the use of these environments rather than a radically distinct set of intentions.

\section{Principle 1: Design space for multiple uses concurrently and consecutively}

- The present approach to facility design emphasises single functions within a facility (eg transcription in lecture theatres, computer-based activity in computer laboratories, nonCIT use in tutorial or small group areas). New learning environments need to allow for multi-functionality. This includes both teacher-centred and student-centred approaches, as well as formal, scheduled classes and informal student use. Student-centred and collaborative approaches to learning, as well as negotiated assessment, will increase the variation in student activity in formal classes.

- Formal locations increasingly need to accommodate informal requirements, when facilities are accessed by students outside of scheduled classes. Radloff (1998) notes that $80 \%$ of student time on campus is spent informally outside scheduled classes. Current oncampus teaching facilities are under utilised when not scheduled for formal classes, leaving students to work in libraries or cafes not generally designed for large numbers of 
students working collaboratively. This is a situation that is both pedagogically and economically untenable.

\section{Principle 2: Design to maximise the inherent flexibility within each space}

- Because of the need for multi-functionality within a class session, it must be possible to quickly re-organise the available site for a particular activity(s). One recent approach to increasing flexibility has been to divide a total area to allow for specific functions (eg formal class, group work, computing, etc). This approach, however, restricts certain activities. For example, CIT access may be required in an area where there are no appropriate facilities, or seating in the designated formal class area may impede group work, discussions and interaction.

\section{Principle 3: Design to make use of the vertical dimension in facilities}

- The predominant architectural paradigm has focused on the function and fit of floor space. Greater use should be made of the options provided by imaginative use of the vertical dimension. For example, walls could be used to provide display areas for subject material or products of research activity, generating a sense of a disciplinary community; or to provide students with whiteboard space for planning, recording and other collaborative activities. Raised floors can be used for performance activities. Ceilings (and, where practical, skylights) can be designed to maximise the informality and aesthetic appeal of particular built environments.

\section{Principle 4: Design to integrate previously discrete campus functions}

- Where practicable facilities should be designed to overcome the present on-campus separation of functions and services. The availability of facilities that provide access to food/drink, communal areas for informal interaction and comfortable furnishings would help to merge social interaction and individual activity for students and others who prefer such an environment.

- Explicit attention should be given to the design of the areas external to the 'built space' to complement and extend the overall learning environment (the 'outdoor classroom'), with covered ways, arcades, cloisters and verandahs provided as a useable transition space between inside and outside.

\section{Principle 5: Design features and functions to maximise teacher \& student control}

- Maximum user (teacher and student) control of the facility's functions should be a premise. Reliance on centrally-provided technical support, as in the case of technical support for video conferencing or computer laboratories, can be a costly and intrusive aspect of formal classes in those locations.

- Technical support is typically prioritised to formal, teacher-led activities which reduces the likelihood of technical support for student-directed informal work undertaken without direct teacher involvement.

\section{Principle 6: Design to maximise alignment of different curricula activities}

- The diverse range of faculties, disciplines, curricula and non-academic activities evident on a university campus requires a variety of learning settings, both formal and informal. For example, a science laboratory might be designed to have a generic student practice area supported by a range of smaller specialist spaces which might be more discipline specific. The aim should be to minimise the larger special purpose labs which are generally under utilised and which can also be a barrier to the introduction of alternative CIT-enhanced pedagogies. 
- All disciplines need to be separately 'interrogated' to determine how the learning objectives are currently achieved, what new approaches are currently under consideration, and what other developments and trends are evident elsewhere which might be influential in time.

\section{Principle 7: Design to maximise student access to, and use and ownership of, the learning environment}

- The general atmosphere of control which most institutions exert over their on-campus facilities is inimical to increased responsibility of students for their own learning experiences and learning outcomes. Student-centred approaches require facilities (libraries, CIT equipped areas, classrooms) which are available to students at times which presently may be thought of as 'out of hours'.

- There is enormous scope to improve the aesthetic dimension of facilities without compromising functionality. The propensity for institutional and standardised architecture should be avoided if we are to encourage critical thinking, and the development of individuals who are actively accepting of difference in our society.

- In spaces that students use regularly, particularly those which are department or faculty specific, students should have significant opportunity to establish a sense of ownership and responsibility for facilities and their maintenance.

In order to determine how these design principles could inform the planning and use of emerging campus physical infrastructure, we will turn to recent developments at two Australian universities.

\section{The ANU 'Learning Studio'}

During the mid-1990s there were a number of new buildings on the Australian National University's capital management plan with a 5+ year planning horizon. A significant proportion of the space in these was devoted to new teaching and learning facilities, most likely involving technology. In 1997 a proposal (Trevitt, 1997) to set up an experimental 'Learning Studio' which piloted an alternative space configuration was accepted. The proposal revolved around testing a furniture configuration for CIT-based teaching and learning spaces which differed significantly from those already in existence (Trevitt, 1999).

In terms of the principles advanced above, we suggest below in Table 1 how the ANU experiences align with the design principles. This account distinguishes between the facilities provided and the actual experience of the users (students and teachers).

\begin{tabular}{|c|c|}
\hline Principle & $\begin{array}{c}\text { Provisions for, and some early experiences with, the ANU } \\
\text { learning studio }\end{array}$ \\
\hline $\begin{array}{l}\text { 1. Design space for } \\
\text { multiple uses } \\
\text { concurrently and } \\
\text { consecutively }\end{array}$ & $\begin{array}{l}\text { Provision: Educational consultative support is available for } \\
\text { academics wanting to reconceptualise the way in which they design } \\
\text { student learning activities, programs and sequences, premised on the } \\
\text { availability of the Learning Studio. } \\
\text { Experience: Academics using the ANU Learning Studio have } \\
\text { embraced a wide range of activities including lectures, 'mini- } \\
\text { lectures', oral reporting by students, video and/or computer-based } \\
\text { presentations, tutorials, workshops, small-group problem-based } \\
\text { learning activities, CIT-based small group work, etc and mixtures }\end{array}$ \\
\hline
\end{tabular}




\begin{tabular}{|c|c|}
\hline & thereof. \\
\hline $\begin{array}{l}\text { 2. Design to maximise } \\
\text { the inherent } \\
\text { flexibility within } \\
\text { each space }\end{array}$ & $\begin{array}{l}\text { Provision: Flat-floored room; } 5 \text { central tables, each with } 5 \text { chairs; } 5 \\
\text { networked desktop computers on desks (with chairs and movable } \\
\text { office screens) located around the perimeter; a ceiling mounted } \\
\text { video and computer projection system; } 3 \text { whiteboards on wheels, } \\
\text { and an overhead projector on a trolley. Internal access to kitchenette } \\
\text { and toilet facilities. } \\
\text { Experience: On the one hand, room layout and furniture } \\
\text { arrangements combine to reinforce the notion of a 'front of the } \\
\text { room' supporting teacher-centred activities. Teachers using this } \\
\text { space have ready access to an overhead display, a video playback } \\
\text { machine and a desktop computer with overhead projection. } \\
\text { On the other hand, student centred work is readily supported through } \\
\text { the use of small group activities at each of the five tables. Students } \\
\text { at each table have access to a networked desktop computer if } \\
\text { required. Teachers can elect to ask students to 'take the floor' and } \\
\text { use any of the facilities available to communicate with the } \\
\text { remainder of the group. }\end{array}$ \\
\hline $\begin{array}{l}\text { 3. Design to make use } \\
\text { of the vertical } \\
\text { dimension in } \\
\text { facilities }\end{array}$ & $\begin{array}{l}\text { Provision: An existing flat-floored room was reconfigured in order } \\
\text { to 'test' the operational functionality of a 'flexible' learning studio. } \\
\text { Experience: Little or no use has been made of the third dimension, } \\
\text { except that there is a ceiling mounted video and computer projector, } \\
\text { and the } 3 \text { whiteboards can be used as 'room dividers'. }\end{array}$ \\
\hline $\begin{array}{l}\text { 4. Design to integrate } \\
\text { previously discrete } \\
\text { campus functions }\end{array}$ & $\begin{array}{l}\text { Provision: The Learning Studio is one component of a greater } \\
\text { whole, comprising kitchenette, toilets and an additional seminar } \\
\text { room. Further flexibility follows from the } 24 \text { hour outside access } \\
\text { capability. } \\
\text { Experience: As indicated in item '1' above, there is a variety of } \\
\text { teaching approaches and learning activities that are readily } \\
\text { integrated into student activity programs in the Learning Studio. } \\
\text { Virtually all of these have historically been associated with discrete } \\
\text { architectural entities such as lecture halls, tutorial rooms, science } \\
\text { laboratories, computer rooms, etc. Some specific uses (eg weekend } \\
\text { intensive language schools) have explicitly capitalised on this } \\
\text { capability to permit seamless integration and overlapping between a } \\
\text { variety of learning activities, access to food and drink, social } \\
\text { interaction and informal 'breakout' activities. }\end{array}$ \\
\hline $\begin{array}{l}\text { 5. Design features } \\
\text { and functions to } \\
\text { maximise teacher- } \\
\text { student control }\end{array}$ & $\begin{array}{l}\text { Provision: There is teacher-student (local) control of computer and } \\
\text { video display options, software applications (within the range } \\
\text { governed by those installed centrally). There is central control and } \\
\text { maintenance of the IT infrastructure, networking environment, } \\
\text { software installations, air-conditioning and student IT servers. } \\
\text { Experience: Apart from exercising control over what is displayed, } \\
\text { and when, local users also determine the extent to which time is } \\
\text { spent in peer discussion, working with CIT applications or networks, }\end{array}$ \\
\hline
\end{tabular}




\begin{tabular}{|c|l|}
\hline $\begin{array}{l}\text { 6. Design to maximise } \\
\text { alignment of } \\
\text { different curricula } \\
\text { activities }\end{array}$ & $\begin{array}{l}\text { or listening to a speaker. } \\
\text { Provision: Educational consultative support is available for } \\
\text { academics wanting to reconceptualise the way in which they design } \\
\text { student learning activities, programs and sequences, premised on the } \\
\text { availability of the Learning Studio. } \\
\text { Experience: Significant work to this end has been invested by at } \\
\text { least one academic who completely redesigned a semester long } \\
\text { curriculum premised on the availability of this facility. Others have } \\
\text { rearranged smaller components of courses (see Trevitt, 1999). }\end{array}$ \\
\hline $\begin{array}{l}\text { 7. Design to maximise } \\
\text { student access to, } \\
\text { ownership of, the } \\
\text { learning } \\
\text { environment }\end{array}$ & $\begin{array}{l}\text { Provision: At this stage of the institutional experiment' represented } \\
\text { by the Learning Studio initiative, this room is generally still } \\
\text { artificially restricted to formal supervised use. This is primarily } \\
\text { because the room and adjacent facilities are not completely secure, } \\
\text { and thus currently are not listed as a general and widely accessible } \\
\text { facility. }\end{array}$ \\
$\begin{array}{l}\text { Experience: While 24 hour access is theoretically possible, for the } \\
\text { reasons identified above, this is currently constrained to staff } \\
\text { including post-graduate tutors) only, and there has been no } \\
\text { significant promotion of student ownership to date. Some limited } \\
\text { informal use by students has been arranged on a needs basis by } \\
\text { some academic staff. There has been some pressure from students to } \\
\text { decrease restrictions on access, suggesting that the facility is } \\
\text { desirable for informal use. }\end{array}$ \\
\hline
\end{tabular}

Table 1. An account the ANU Learning Studio in terms of the design principles

\section{The Victoria University of Technology 'rural' campus}

The Victoria University of Technology in partnership with the local aboriginal community, is conducting a four-year Bachelor of Education program, open to both aboriginal and nonaboriginal students, on the site of a former commercial bank building in rural Victoria. The integration of pedagogical and architectural concerns by the teaching team reflects many of the key principles identified above. Like the ANU Learning Studio, this initiative illustrates the implementation of a built environment designed to support a specific view of learning, and also acknowledges the significance of the cultural context in which it operates. The program coordinator said:

The basic organising principle underlying [the program] in terms of teaching and learning, is the concept of inquiry....The main features involve: respect for knowledge and each other, democratic procedures, informal relationships, emphasising practice first and then trying to develop our understanding of practice through personal theorising, recognising the holistic cultural experience of students and their families, strong connections with the community, learning from the land and waters. Ready access to the environment, whether the rivers or forests, is a major feature of the program. Out of this approach comes a learning setting and building arrangement that is integrated and informal. For example, it is intended that Year 1 and Year 2 subjects will continue to run together, so that learning is co-operative. The sense and practice of community must be found in the setting, i.e., not broken up into 'boxes.' IT needs to be utilised in the same way, available to be used as required for access to information and communication. Appropriate space for student activities 
such as sport, eating, reading, discussion and researching, must also be integrated. (Personal correspondence)

Fortuitously the building comprises a large open space with several rooms around the perimeter. The teaching team used one room as a kitchenette where people could make that all-important cup of tea or coffee. The program coordinator used what was probably the bank manager's office as her office. Computer equipment was placed in a third room and along one of the walls of the main room. What remained was an empty space, which the teaching staff and students could use in their preferred ways. The equipment such as overhead projectors and white board was mobile and the group used portable partitions to separate parts of the room. Chairs and tables could be rearranged as required. Approximately forty students attended the learning centre throughout 1999.

The teaching team's perspective on teaching is integral to the evolution of this newly adapted campus facility where the emphasis is on student-centred approaches to learning. First, the teachers recognised that students learn both in formal and informal settings. Secondly, the teacher served as a facilitator of student learning rather than as a transmitter of knowledge. Thirdly, knowledge was socially constructed as students talked to their peers and the aboriginal elders of the local community. Consequently, different narratives including those from indigenous communities informed this learning community's knowledge construction.

The students in the program were actively encouraged to take ownership of their own learning and to use the building in ways that best met their goals at the time. There were formal tutorials but more often teachers undertook small group tutorials while other students worked on their various projects with other students or individually. Individual inquiry and collaboration at the students' own pace was actively encouraged although there were some deadlines to meet. Consequently, people moved furniture to accommodate the purpose of an activity and the number of students participating. Furthermore, teaching not only took place on campus but also in the surrounding parklands to take advantage of the group's associations with the land.

The approach to using the facility is congruent with the principles we have identified. Being essentially a large open room, furniture could be readily moved by participants according to need. The teachers and students had local control of a learning space which accommodated different learning activities occurring simultaneously. If staff were available, the centre was often open for extended hours, and at times, staff conducted programs during the evening for adults unable to attend during the day. Students had scheduled classes but they were also encouraged to work on campus at anytime. Being remote from a major VUT campus, the learning space needed to include a kitchenette and toilets. The local shops acted as the 'campus' cafeteria. The pivotal feature of the program was that students were encouraged to take ownership of their learning and, consequently, their physical environment and teachers had considerable autonomy to determine the way the facility would be used.

\section{Looking to the future}

This paper has focused on issues of space and place in the changing context of university teaching. It reflects our conviction that these elements of the learning environment have largely been treated in isolation from the developments in the pedagogical practices that universities seek to achieve. Current developments in the design of space and of pedagogy have yet to reach alignment with each other and with other significant elements in these new learning environments, as other papers in this edition of HERD amply illustrate. In this section of the paper we turn our attention to the development of such alignment. 
More appropriate on-campus facilities are most likely to result from a deliberate effort to observe and learn from the way teachers and students use existing and new teaching and learning built environments. The difficulty lies in implementing such an approach when resources are already scarce. One solution may be found in the field of theatrical stage design. In contrast to the current practice of single function facilities, we propose the concept of a physical facility that functions as a teaching and learning 'shell'. The concept of a 'shell' draws on the practices of theatrical stage and set design that enable mobility of features and maximum adaptability within a limited spatial environment (and budget). On a teaching and learning stage a more experimental approach to the actual design and fitting of on-campus teaching and learning environments could be explored, along the lines of the ANU Learning Studio. It could also serve to highlight the performative aspects of on-campus pedagogy.

What would be the characteristics of such a facility? In line with the principles outlined above it should provide a physical location within which teachers and students can engage in ways appropriate to a range of subject areas. There would be much greater scope to customise the fittings and fixtures to meet the needs of specific user groups. In such a space there would need to be much greater flexibility in the integration of CITs (as required) to avoid the creation of superfluous barriers to movement and interaction when not required. Such a facility would provide a single site to inform the design and implementation of new teaching and learning environments for an entire institution or for individual faculties. Unnecessary duplication within faculties would be avoided and a more institution-wide and strategic approach to the implementation of new facilities could be adopted.

This would essentially create a teaching and learning workshop (implied in the emerging architectural idea of a 'loose fit' building) where the physical environment allowed for adaption and experimentation with a range of teaching and learning approaches. Within this flexible setting, teaching practices and student behaviour could be explored together with the relationship of the users to the physical environment. Questions which might underpin such exploration could include: How do students function in certain arrangements of facilities? How do they choose to set up a room for their own us in collaborative learning environments? How do they use the technology and what do they do with it? How do teachers teach more collaboratively as they move from traditional, single teacher classrooms to environments where more than one teacher is directly involved in the teaching process?

To achieve this shift in approach to strategic planning a major change is required on the part of university facility managers. Staff and students would need to have the right to shape their places of teaching and learning in much the same way as they shape the curriculum. The financial, occupational health safety and welfare, technological, staffing, research, energy, services and administrative devolution to academic departments which has occurred in the past decade would need to expand to include the design and management of the built environments in which all of these activities are carried out. Only then will the relationship between teaching, learning, CITs and built places be both aligned and integrated. Without a radically different approach to the pedagogy-place nexus, the massive shift to student-centred, flexible learning being driven by the new CITs, will be destined to take place in a physical environment built in another time and for another purpose.

\section{References}

Bachelard, G, (1964). The Poetics of Space. Boston (Mass.): Beacon Press 
Bagnall, R. (1988). Reconceptualising and revaluing distance education through the perspective of self-direction. In D. Sewart \& J. Daniel (Eds), Developing Distance Education. (Proceedings, 93-95). International Council of Distance Education $14^{\text {th }}$ World Conference, Oslo, 9-16 August.

Biggs, J. (1999). Teaching for quality learning at university: What the student does. Buckingham: SRHE \& Open University Press.

Biggs, J. (1993). From theory to practice: A cognitive systems approach. Higher Education Research and Development, 12(1): 73-85.

Day, N. (1999). The Age, 12 November, Melbourne.

Department of Employment, Education and Training. (1993). Video-Conferencing in Higher Education in Australia: An evaluation of the use and potential of video-conferencing facilities in the higher education sector in Australia. Canberra: Australian Government Publishing Service.

Entwistle, N. \& Ramsden, P. (1983). Understanding Student Learning. London: Croom Helm. Freire, P. (1973). Education for Critical Consciousness. New York: Seabury.

Gillard, G. (1993). Deconstructing contiguity. In T. Evans \& D. Nation (Eds), Reforming Open and Distance Education - critical reflections from practice (pp. 182-195). London: Kogan Page.

Howlin, J. (1999). The Australian Financial Review Magazine. (December, 1999)

Jamieson, P. (1998). How University Teachers Experience Teaching by Cross-Campus Video Conferencing: A Phenomenographic Study. (unpublished doctoral thesis, RMIT).

McWilliam, E. \& Taylor, P.G. (1998). Teacher im/material: challenging the new pedagogies of instructional design. Educational Researcher, 27 (8): 29-34.

Marton, F. \& Booth, S. (1997). Learning and Awareness. New Jersey: Lawrence Erlbaum Associates.

Marton, F. \& Saljo, R. (1976). On qualitative differences in learning 1: Outcomes and process. British Journal of Educational Psychology, 46: 115-127.

Merkel, C. (1999). Folkloristics of Educational Spaces: Material Lore in Classrooms with and without Walls. Library Trends, 47: 417-430.

Moffatt, S. \& Flynn, L. (1998). Student interaction in an electronically mediated classroom: Results, issues and potential. Open Learning 98, Brisbane, pp. 409-413 (Proceedings).

Prosser, M. \& Trigwell, K. (1999). Understanding Learning and Teaching: The Experience in Higher Education. Buckingham: SRHE \& Open University Press.

Radloff, P. (1998). Do we treat time and space seriously enough in teaching and learning? In Black, B. and Stanley, N. (Eds), Teaching and Learning in Changing Times. Proceedings of the 7th Annual Teaching Learning Forum. The University of Western Australia, February 1998. Perth: UWA.

Available at: http://cleo.murdoch.edu.au/asu/pubs/tlf/tlf98/radloff-p.html

Ramsden, P. (1992). Learning to Teach in Higher Education. London: Routledge.

Rollo, J. (1996). The Age, 13 July, Melbourne.

Ryan, Y. \& Tapsall, S. (1998). New media and borderless education: Open Learning 98, Brisbane, pp. 431-437 (Proceedings). 
Scheer, B \& Preiser, F.E. (1994). Design Review: Challenging the Urban Aesthetic Control. Chapman and Hall.

Taylor, P.G. (1996). Pedagogical challenges of open learning: looking to borderline issues. In Pedagogy, Technology and the Body. Edited by Erica McWilliam and Peter G. Taylor. Peter Lang Publishing Inc.: New York. pp 59-77.

Trevitt, A.C.F. (1997). A prototype learning studio at the ANU: toward a new infrastructure configuration which offers more with less. ANU internal discussion paper. Available at: http://www.anu.edu.au/CEDAM/learningstudio.html

Trevitt, A.C.F. (1999). Catalysing collaborative initiatives in computer-supported collaborative learning: a case study and formative evaluation of the on-going ANU Learning Studio initiative. Paper presented at the annual national conference of HERDSA, July 12-15, Melbourne.

Available at: http://herdsa.org.au/vic/cornerstones/pdf/Trevitt.PDF

Worthington, L. (1999). The Distance Education Online Symposium [DEOSL@lists.psu.edu]. Personal message to online discussion group, accessed 9/11/99. 